\title{
Itinerários terapêuticos de pacientes com diagnóstico de hanseníase em Salvador, Bahia
}

| ${ }^{1}$ Patricia Vieira Martins, ${ }^{2}$ Jorge Alberto Bernstein Iriart |

Resumo: A hanseníase e seu diagnóstico tardio, que favorece o agravamento dos sintomas e o surgimento de sequelas físicas, permanecem como um grave problema de saúde pública no Brasil. O objetivo deste artigo é analisar o itinerário terapêutico de pessoas com hanseníase, buscando compreender sua experiência da enfermidade, assim como os fatores que contribuíram para o diagnóstico tardio. Foram realizadas 18 entrevistas narrativas com pacientes em tratamento de hanseníase na cidade de Salvador, Bahia, entre 2009 e 2011. Os resultados apontam que, na maioria dos casos, os pacientes percorreram um longo itinerário terapêutico até a realização do diagnóstico. Entre os fatores que contribuem para o diagnóstico tardio está falta de capacitação dos profissionais de saúde nos serviços de saúde para diagnosticar precocemente a enfermidade, assim como o estigma e o preconceito, que favorecem o silêncio em torno da doença e a automedicação.

> Palavras-chave: hanseníase; itinerário terapêutico; análise de narrativa.

\author{
1 Fisioterapeuta, Doutorado \\ em Saúde Pública pela UFBA; \\ Mestrado em Saúde Pública \\ pela UFSC. Endereço eletrônico: \\ patriciavmartins@hotmail.com \\ 2 Doutor em Antropologia \\ pela Universidade de Montreal \\ (Canadá). Professor associado \\ do Instituto de Saúde Coletiva \\ da UFBA. Endereço eletrônico: \\ iriart@ufba.br
}

Recebido em: 14/08/2013 Aprovado em: 15/01/2014 


\section{Introdução}

A hanseníase permanece como um grave problema de saúde pública no Brasil, sobretudo nas regiôes Norte, Nordeste e Centro-Oeste (BRASIL, 2011). A doença atinge pele e nervos e apresenta quatro formas clínicas: tuberculóide, dimorfa, virchowiana e indeterminada. Os sinais e sintomas mais evidentes são manchas, falta de sensibilidade, câimbras, dores musculares, espessamento de nervos, limitações na visão, marcha com dificuldade e encurtamentos de nervos, músculos e articulações (TALHARI; NEVES, 1997). O tratamento implica a utilização de medicação durante seis ou doze meses, dependendo do diagnóstico apresentado pelo paciente: forma paucibacilar -apresentando até cinco sinais da doença - ou multibacilar - apresentando mais de cinco sinais da doença (VERONESI, 1996; SANTOS, 1990). Em 2011, foram identificados como registro ativo 29.690 casos de hanseníase no país, sendo a prevalência de 1,54 casos para cada 10.000 habitantes. Na região Nordeste, foram identificados 12.575 casos como registro ativo, sendo a prevalência de 2,35 casos para cada 10.000 habitantes (BRASIL, 2011).

O diagnóstico da hanseníase apresenta algumas dificuldades e muitas vezes o quadro clínico é confundido com o de diversas dermatoses, sendo o diagnóstico tardio um problema grave associado à doença. A demora no início do tratamento em decorrência do retardo no diagnóstico pode causar importantes sequelas físicas, deixando o paciente com limitações em suas atividades da vida diária. O estudo de Gonçalves, Sampaio e Antunes (2009) evidencia a importância do diagnóstico precoce para o controle da neuropatia silenciosa, o qual impede a instalação de um grau de incapacidade permanente. Sequelas físicas, aparentes ou não, causam limitações em diversas dimensões na vida dessas pessoas e contribuem para aumentar o preconceito e o estigma que recaem sobre elas, os quais, como mostram vários estudos em diferentes contextos socioculturais, ainda são muito fortes e disseminados (NATIONS; LIRA; CATRIB, 2009; MINUZZO, 2008; BARRET, 2005; NICHOLLS; WIENS; SMITH, 2003).

A revisão da literatura aponta, no entanto, a quase inexistência de estudos que abordem o itinerário terapêutico vivenciado por pacientes com hanseníase, que poderiam permitir compreender melhor os fatores que contribuem para o diagnóstico tardio, além de abordar dimensões da experiência da enfermidade. 
Entendemos por itinerário terapêutico as escolhas, as avaliações e as "aderências" feitas pelos indivíduos a determinadas formas de tratamento (ALVES; SOUZA, 1999), sendo importante sinalizar que esse itinerário não se limita à identificação e à disponibilidade dos serviços de saúde oferecidos, mas está relacionado às diferentes buscas individuais e às possibilidades socioculturais de cada paciente. $\mathrm{O}$ itinerário terapêutico inclui uma sequência de decisões que podem ser individuais ou contar com a participação de vários indivíduos com diferentes interpretações sobre a identificação da doença e do tratamento correto a ser seguido (MATTOSINHO; SILVA, 2007). Ele retrata o percurso seguido em busca do tratamento e da cura, e até mesmo as avaliações equivocadas em torno dos diagnósticos obtidos (NEVES; NUNES, 2010). Observando os relatos sobre itinerários, destacamos, também, a aflição e a experiência dos pacientes (MALISKA; PADILHA, 2007).

A antropologia da saúde tem abordado a experiência da enfermidade considerando que toda doença está envolta em uma rede de significados construídos intersubjetivamente. A significação dessa experiência tornou-se bastante relevante, levando-se em consideração como os pacientes expressam, organizam e compreendem sua aflição (ALVES; RABELO; SOUZA, 1999). A busca de ajuda terapêutica só ocorre a partir do momento em que a pessoa interpreta aquilo a que Kleinman (1978) denomina "estados socialmente desvalorizados" (que não necessariamente se restringem à patologia) como um problema de saúde que demanda a busca de ajuda terapêutica.

O objetivo deste artigo é, a partir de uma perspectiva socioantropológica, analisar o itinerário terapêutico de pessoas com hanseníase, buscando compreender sua experiência e os significados que orientaram sua busca por ajuda, assim como os fatores que contribuíram para o diagnóstico tardio. Em outras palavras, buscase investigar, a partir das narrativas desses pacientes, quais foram os primeiros sinais e sintomas identificados por eles e reconstruir sua trajetória terapêutica até o diagnóstico de hanseníase.

\section{Itinerários terapêuticos}

A partir de uma perspectiva socioantropológica, podemos compreender que o estado de saúde pode ser associado ao modo de vida e aos universos social e 
cultural de cada cidadão (UCHÔA; VIDAL, 1994). Segundo Alves (1993), a "experiência da enfermidade" faz referência à forma como os indivíduos ou os grupos sociais respondem a um dado episódio de doença. $\mathrm{O}$ autor parte da premissa de que os interlocutores (re)produzem conhecimentos médicos existentes no universo sociocultural em que se inserem. Para Kleinman (1988), a narrativa da enfermidade é uma história contada e recontada pelo paciente para dar coerência a eventos distintos, e que não apenas reflete a experiência da enfermidade, mas contribui para a experiência dos sintomas e do sofrimento.

Freidson (ALVES, 1993) deu importante contribuição para o estudo dos itinerários terapêuticos propondo o conceito de "sistema leigo de referência" (no qual o sujeito desencadeia uma sequência de práticas destinadas a uma solução terapêutica). O autor relata que, quando um indivíduo é "definido" como doente, desenvolve uma sequência de práticas com o objetivo de buscar uma solução terapêutica. Chama-se esse processo de "carreira da enfermidade" (career of illness).

O estudo dos itinerários terapêuticos tem sido utilizado por pesquisadores em estudos recentes para compreender as trajetórias de sujeitos com diferentes enfermidades. Fundato et al. (2012) fizeram um estudo com dezesseis indivíduos com câncer, no Instituto de Oncologia Pediátrica de São Paulo, e analisaram seus itinerários terapêuticos, assim como a percepção da enfermidade por parte deles e de seus familiares. Evidenciou-se que, em alguns casos, os interlocutores tiveram diagnósticos equivocados, talvez por não perceberem sinais e sintomas associados à patologia, e que a família tem forte influência sobre qual ajuda terapêutica buscar e que tratamento seguir. Esses equívocos levaram alguns pacientes a se automedicarem, retardando o diagnóstico da doença e o início do tratamento. Essa demora em obter o diagnóstico correto também pode estar relacionada às falhas do sistema de saúde, que envolvem falta de profissionais capacitados para detectar o mais imediatamente possível a doença e sistema precário de referência para o tratamento de câncer. Pinho e Pereira (2012) compreenderam o itinerário terapêutico como percursos percorridos pelos indivíduos em busca de ajuda para restabelecer a saúde. Nessa trajetória, esses indivíduos traçam planos e açōes para lidar com a enfermidade. Nesse trabalho, realizado com pacientes vivendo com Aids no estado de São Paulo, notou-se que, embora eles sigam o tratamento biomédico, as práticas religiosas ocupam importante papel em sua experiência, o que faz surgirem diferentes interpretaçooes em relação à doença, influenciando os itinerários terapêuticos. 
A revisão da literatura aponta que a maior parte dos estudos sobre hanseníase tem abordado o tema do estigma. Apenas um estudo enfocou o itinerário terapêutico, ainda assim, em uma perspectiva distinta da do presente estudo. Lins (2010), em pesquisa realizada em São Domingos do Capim, na Amazônia, reconstrói o itinerário terapêutico de 12 indivíduos com hanseníase e sinaliza a importância de considerar a interpretação dos significados da doença dados pelos pacientes para se compreender como ocorre a busca de ajuda terapêutica. Evidencia, assim, que o controle da endemia estará diretamente associado à compreensão das interpretações e práticas dos doentes, possibilitando uma relação dialógica entre profissionais da saúde e população local.

\section{Método}

Trata-se de um estudo qualitativo de cunho socioantropológico, cuja produção de dados se deu por meio de entrevistas em profundidade, de tipo narrativo, com 18 pacientes com diagnóstico de hanseníase entre 2009 e 2011. A pesquisa foi realizada no ambulatório de dermatologia do Complexo HUPES (Hospital Universitário Professor Edgard Santos), em Salvador-Bahia. O ambulatório funciona um dia por semana, em um turno, e conta com uma equipe de seis residentes, uma enfermeira, uma farmacêutica e quatro profissionais para funções administrativas - marcação de consultas e auxílio no atendimento. Conta também com grupos de pesquisas e os voluntariados de um professor de patologia (para auxiliar os residentes nos estudos das células) e de dois fisioterapeutas.

No geral, são atendidos de 30 a 60 pacientes por semana, mas o ambulatório não consegue dar conta da demanda. Como se trata de um hospital-escola e um centro de referência, o atendimento deveria centrar-se nos casos graves e com surtos reacionais, mas, na prática, o ambulatório tem atendido todos os tipos de casos.

A inserção da primeira autora no ambulatório deu-se em agosto de 2010, em trabalho voluntário, realizando a ficha para prevenção de incapacidade física. Com formação em fisioterapia, a primeira autora trabalhou por sete anos na atenção básica no estado de Mato Grosso do Sul, dois deles especificamente com hanseníase.

O trabalho de campo teve início em 2011 e se estendeu até agosto de 2012. Para a seleção dos participantes, foram utilizados os seguintes critérios: ser maior de 18 anos, estar seguindo o tratamento no ambulatório de dermatologia do Complexo HUPES e se disponibilizar a participar da pesquisa. 
A composição do corpus buscou refletir a heterogeneidade dos pacientes no ambulatório, levando em conta: sexo, faixa etária, escolaridade, renda, estado civil e aposentadoria ou não devido à doença. As entrevistas foram gravadas em microcassete e tiveram, em média, duração aproximada de uma hora. Algumas entrevistas foram realizadas no ambulatório, na sala da enfermagem, cedida fora do horário de atendimento normal. Outras entrevistas foram realizadas no pátio do hospital, na praça de alimentação da faculdade de música (próxima ao hospital da pesquisa), na casa de alguns pacientes ou em algum local próximo ao hospital escolhido por eles, respeitando sua privacidade e seus horários de trabalho.

No contato com os pacientes, a primeira autora se apresentou como pesquisadora e estudante de doutorado. No decorrer dos meses, ao longo do trabalho de campo, a relação com os pacientes entrevistados foi se tornando mais próxima e eles se mostraram muito à vontade para responder às questôes nas entrevistas. Muitos deles passaram a procurar a pesquisadora antes do atendimento para relatar fatos ocorridos em suas vidas, contar sua rejeição no emprego ou como estavam suas relações familiares e conjugais.

Segundo Jovchelovitch e Bauer (2002), a entrevista narrativa pode ser considerada uma entrevista com perguntas abertas. A partir de questôes iniciais disparadoras, o pesquisador deixa o entrevistado falar livremente e vai encorajando-o a aprofundar os temas que surgem no fluxo da conversa. Algumas questóes abertas norteadoras da entrevista foram: Quando o senhor descobriu que estava doente? Como foi sua trajetória na busca do tratamento? O que mudou em sua vida após o diagnóstico?

Para a análise de dados, utilizamos a análise de narrativa, que, segundo Bury (2001), permite analisar as maneiras pelas quais os leigos gerenciam doenças crônicas na vida cotidiana. Apesar da hanseníase ter cura, alguns pacientes precisam estender o tratamento tradicional - de seis ou doze meses - para vários anos, realizando tratamento de surto reacional. É possível classificar a hanseníase, nesses casos, como uma doença "crônica". No estudo das doenças crônicas, Bury (2001) dá ênfase à continuidade e à descontinuidade (como era e como ficou a vida do paciente após a enfermidade). A análise buscou evidenciar os significados que orientaram as escolhas terapêuticas dos pacientes e sua experiência da enfermidade. 
A pesquisa foi aprovada pelo Comitê de Ética em Pesquisa com Seres Humanos do Instituto de Saúde Coletiva da Universidade Federal da Bahia (Protocolo no 046-11) e pelo Comitê de Ética do HUPES (Protocolo no 13-2012). Todos os participantes assinaram o Termo de Consentimento Informado e todos os nomes citados são fictícios.

\section{Os participantes da pesquisa}

Os 18 pacientes entrevistados tinham idade entre 25 e 80 anos. Quatorze entrevistados tinham ensino fundamental incompleto, um tinha ensino médio completo e apenas três completaram o nível superior. Metade dos participantes residia em Salvador e a outra metade em outros municípios da Bahia (Euclides da Cunha, Camaçari, Valença, Entre Rios, Itabuna, Lauro de Freitas e Ilha de Coroa). Todos compareciam ao ambulatório uma vez por mês para buscar medicamento e, se necessário, fazer revisões.

Oito desses indivíduos eram solteiros, três separados, seis casados e um viúvo. Doze declararam ter renda de um a dois salários mínimos, dois cinco e oito salários mínimos e três acima de oito salários mínimos. Os que exerciam algum tipo de atividade remunerada relataram diversas ocupaçóes: costureira, trabalhadora doméstica, carpinteiro, professor, pedreiro, pintor, auditor fiscal, motorista, carregador, comerciante, farmacêutico e técnico de enfermagem. Dois pacientes estavam aposentados antes do diagnóstico e duas pacientes se definiram como "do lar".

\section{Resultados e Discussão}

\section{Os itinerários terapêuticos}

Como mostra a antropologia médica, para a busca de ajuda terapêutica é necessário que o paciente reconheça que tem um problema e o identifique como um problema de saúde (KLEINMAN, 1978). Os principais sintomas que levaram os entrevistados a buscar ajuda terapêutica foram: a presença de manchas no corpo (dez interlocutores; sendo cinco com manchas pelo corpo, dois no rosto, um no pé, um na coxa esquerda e um na cabeça), dormências (sete interlocutores; três com dormência nos pés, dois nas mãos, um na perna e um 
no braço) e, em menor número, corpo inchado (dois interlocutores) e dores nas articulaçôes (dois interlocutores):

Era a dormência no pé. Começou nos dedos, e daí fiz exame dos pés, exame das veias e não dava nada, ninguém descobria o que era, e minha perna dormente. Fazia outros exames, tirou radiografia, e nada (Melissa, 55 anos, costureira).

Andando, sentia essa dormência na perna, essa dormência que não tô aguentando nem andar. Eu vinha de sandália e perdia ela no ônibus, saí e vi que tava descalço, faltando um pé (Emerson, 55 anos, carpinteiro).

Eu comecei a sentir uma dor no meu cotovelo direito, eu batia muito no carro, batia o cotovelo no carro (Ana, 50 anos, farmacêutica).

Após o aparecimento dos primeiros sinais e sintomas, vários entrevistados recorreram à automedicação buscando ajuda nas farmácias, mostrando as manchas e recebendo indicações de pomadas. Outros receberam indicações de analgésicos para as dores e injeçóes de penicilina. Outros confundiram as manchas com dermatoses e as dormências e câimbras com doenças reumatológicas. Em um dos casos, o paciente havia feito um tratamento de linfoma. Assim, achou que as dormências que estava sentindo eram decorrência da primeira patologia, sequela do tratamento de câncer.

Vários interlocutores não deram muita importância para esses sinais, sintomas e limitações aparentes. Alguns trataram as manchas como uma "coisinha sem importância”, pois não incomodavam. Algumas dessas manchas demoraram muito para se desenvolver, crescer e mudar de tonalidade. A automedicação contribuiu para o retardo na busca de ajuda médica, que só ocorreu quando os sinais e sintomas se tornaram mais evidentes. A decisão de buscar ajuda médica ocorreu apenas quando os sintomas realmente persistiram e incomodaram (coçando, ardendo, aumentando) ou assumiram um aspecto feio, chamando a atenção das pessoas pela limitação física.

O estigma e o preconceito em relação à hanseníase contribuem para o silêncio em torno da doença e o desconhecimento dos sintomas que a caracterizam entre a população. Metade dos entrevistados nunca conheceu ninguém que tivesse hanseníase. A outra metade, no entanto, relatou que já havia tido alguma relação com alguém infectado: vizinho, irmão, amigo, ex-namorada, filho ou primo. Muitos identificavam algum conhecido que teve a doença apenas depois que o médico os orientava a trazer os comunicantes (pessoas conhecidas ou familiares que morassem na mesma casa ou tivessem uma convivência muito próxima). 
Goffman (1988) define estigma como um atributo com significado depreciativo associado a quem o porta. Esse atributo é utilizado pela sociedade para desqualificar ou desvalorizar a pessoa, uma vez que é entendido como defeito, fraqueza ou desaprovação, levando frequentemente a discriminação e a violação dos direitos humanos. Com medo de serem estigmatizados, os pacientes entrevistados evitaram revelar o diagnóstico e falar sobre a doença, que ainda é um tabu. As pessoas com sintomas e sem diagnóstico nem sequer cogitam a possibilidade de serem portadoras de hanseníase. Entre os entrevistados, a maioria comunicou o diagnóstico apenas aos familiares mais próximos. Uma entrevistada revelou sua doença apenas ao marido e à filha mais velha, isso porque esta a levava para realizar o tratamento. Os demais filhos não ficaram sabendo. Houve um caso em que a paciente não contou para ninguém da família que tinha ficado doente, ocultando dos pais e irmãos. A única pessoa que ficou sabendo da sua doença e do tratamento foi uma vizinha, que também a acompanhou em algumas visitas ao médico.

Eu não tenho coragem de dizer que eu tive hanseníase. Por medo. Será que eles vão me ver da mesma forma? Não sei, daí eu fico com medo (Michelle, 35 anos, aposentada, solteira).

Não, nunca falei detalhes. Falo só que estou fazendo tratamento, mas nunca entrei em detalhes, só pra minha família. Tenho medo (Gerson, 59 anos, casado aposentado).

Se eu falar, 90\% dos leigos vão achar que é uma doença altamente contagiosa, então, aquela coisa toda, medo também, preferi me silenciar (Kleber, 75 anos, casado, auditor fiscal aposentado).

Eu não digo a ninguém que eu tenho isso. Eu tenho medo das pessoas ficarem achando que isso pega. Aí eu não falo (Arlete, 40 anos, solteira, doméstica, serviços gerais).

Com medo do estigma e do preconceito, os pacientes entrevistados escolheram realizar o tratamento em um hospital de referência mais distante, evitando fazêlo em unidades básicas de saúde próximas a suas residências. Romero-Salazar et al. (1995), em estudo realizado no Serviço de Dermatologia Sanitária em Maracaibo, na Venezuela, observaram que $85 \%$ dos indivíduos esconderam que estavam doentes temendo o abandono, a demissão de seus empregos ou o "rótulo" de anormais. Alguns usavam roupas para disfarçar manchas e lesões, e, quando tinham que ir aos Hospitais de Referência, agiam de modo discreto, apresentando-se sem nenhum acompanhante. 
O receio dos entrevistados em revelar o diagnóstico não é infundado. Todos enfrentaram algum tipo de preconceito e estigma após a revelação do diagnóstico. Alguns foram demitidos, outros discriminados em sua própria família nuclear. Perpassando as narrativas, transparece o medo do contágio associado à doença que não cede mesmo após o paciente estar em tratamento ou curado. Palmeira, Queiroz e Ferreira (2012), em estudo realizado em uma unidade de referência especializada em dermatologia sanitária, no município de Marituba-Pará, apontam que no imaginário das pessoas a hanseníase se transmite através do beijo, do toque e do uso em comum de objetos domésticos.

A pessoa que teve hanseníase fica estigmatizada como uma fonte de contágio em potencial, provocando receio e atitudes defensivas por parte das pessoas:

Chegava perto de mim e ficava com aquela coisa, com medo. Quando eu ia tomar uma água, aí ficava: nesse copo não beba, quando beber sua água, separa seu copo! Quando você for comer você separa seu prato! Aquela coisa... (Felipe, 28 anos, solteiro, carregador).

Minha esposa ficou assustada e eu separei porque ela ficou assim comigo, com medo, daí não adianta mais esse relacionamento. Ela nem me tocava (Emerson, 55 anos, separado, carpinteiro).

Minuzzo (2008), em estudo realizado nos municípios de Duque de Caxias, Niterói e Petrópolis, no estado do Rio de Janeiro, com pacientes do sexo masculino que tinham a forma multibacilar da doença, mostrou a grande vulnerabilidade social vivenciada por eles e sinalizou que o medo da discriminação foi expresso por todos os participantes da pesquisa. Barret (2005), em estudo realizado na Índia, mostra que a discriminação ainda é forte sobre os indivíduos que apresentam sequelas decorrentes da hanseníase, que são banidos do convívio social.

O estigma e o preconceito existentes em torno da doença também são fatores que contribuem para a demora na busca de ajuda médica e para o retardo do diagnóstico correto. Nicholls et al. (2003), em pesquisa realizada no Paraguai, constataram que, quando os sujeitos desconfiam estar com hanseníase, temendo serem estigmatizados, evitam os serviços de referência em atenção básica, buscando, em princípio, a ajuda de curandeiros ou benzedeiras tradicionais. Muito tempo depois é que há interação com os serviços de saúde, trazendo como consequência o diagnóstico tardio e o agravo da enfermidade.

Chamam a atenção nas narrativas o longo itinerário terapêutico e os vários diagnósticos equivocados recebidos por muitos pacientes entrevistados. Embora 
muitos dos sintomas apresentados sejam "clássicos" da hanseníase, mais da

metade desses interlocutores tiveram que apresentar uma grave progressão da doença para obter os diagnósticos corretos.

Ele fazia os exames e não descobria nada. Dizia: não, a senhora não tem nada. Fiz exames dos nervos... (Melissa, 55 anos, costureira).

Em 98 começou a aparecer umas manchas no meu corpo [sic], mas eu ia para o dermatologista, ele passava um remédio e não descobria o que era. Aí em 99, 2000, 2001, meu patrão mandou eu vir pra aqui, pro Hospital das Clínicas. Mas foi constatado em 2003. Comecei a fazer o tratamento mesmo de hanseníase em $1^{\circ}$ de outubro de 2003 (Michelle, 35 anos, aposentada).

Eu fui a um dermatologista e ele tava achando que era uma alergia, fui passando num e no outro, até que foi piorando a situação, eu ia para praia e quando chegava estava cheio de calombo nas costas, manchas começando, ficando mais vermelho (Ademar, 60 anos, pedreiro).

Fui ao dermatologista, o dermatologista passou uma pomadinha corticoide e ai eu já perguntei pra ele se aquilo não poderia ser hansen e ele me disse que não. Me lembro que ele passou o dedo aqui, ó, e disse: tenho quase 30 anos de profissão e isso não tem nenhuma possibilidade de ser hansen! (Ana, 55 anos, farmacêutica).

Demorou uns 10 anos. Foi porque quando eles passavam um remédio eu voltava lá, diminuía e parecia que ia ficar bom. Mas com o passar do tempo, aos pouquinhos ela vinha ressurgindo e no mesmo lugar que parecia que tava são e aí não teve como (Marcelo, 55 anos, motorista).

Antes de iniciarem o tratamento no ambulatório de referência, além de dermatologistas, os entrevistados relataram ter procurado também outros especialistas, tais como clínicos, ortopedistas, reumatologistas e angiologistas. Inicialmente, isso ocorria perto de suas residências e de suas cidades. Como o diagnóstico não era feito da maneira correta, ou seja, a doença não era identificada, eles procuraram tratamento em outra cidade. Interlocutores residentes no interior da Bahia começaram a frequentar inicialmente os ambulatórios de Salvador. Vários passaram por diferentes postos de saúde e hospitais antes de chegarem a um dos dois centros de referência em hanseníase, onde finalmente receberam o diagnóstico. Os principais diagnósticos equivocados relatados por esses interlocutores foram: problemas na coluna, problemas circulatórios, alergias e outras dermatoses. Uma paciente descobriu a doença por acaso, pois foi até o dermatologista verificar umas manchas brancas no braço, achando se tratar de câncer de pele. Quando já estava saindo da sala, mostrou a mancha que tinha na coxa, e foi assim que o médico diagnosticou a hanseníase. 
O tempo de diagnóstico desde o aparecimento dos primeiros sintomas, a partir dos relatos dos interlocutores, variou de três a 120 meses (10 anos). O tempo médio foi de 27,4 meses e a mediana, de 18 meses.

De Groot, Van Brakel e De Vries (2011), em estudo realizado na Holanda, abordaram o retardo no diagnóstico da hanseníase, que se estende de 1 a 8 anos. Por se tratar de uma doença rara, de importação, como na maioria dos países desenvolvidos, os médicos não consideram a possibilidade de o paciente ter a doença. Os autores verificaram a falta de informação em torno da hanseníase e a falta de grupos de apoio e de formação dos profissionais de saúde para tratar esses pacientes. Já outro estudo, realizado na área rural de Maharashtra, na Índia, onde a hanseníase é endêmica, observou-se que os pacientes demoravam apenas três meses para receberem diagnóstico, desde a percepção dos primeiros sinais da doença (ATRE et al., 2011). Observa-se a notável diferença no tempo necessário para a realização do diagnóstico, o que está associado à capacitação dos profissionais de saúde e ao fato de, em um dos contextos, a doença ser um grave problema de saúde pública, deixando os profissionais mais alertas para detectarem, diagnosticarem e tratarem os doentes.

$\mathrm{Na}$ maioria dos casos narrados por nossos interlocutores, o diagnóstico só aconteceu rapidamente depois que eles realizaram consulta em um ambulatório ou hospital de referência com um médico especialista em hanseníase. $\mathrm{Na}$ maioria das vezes, o tratamento teve início no mesmo dia, ou, por uma questão de aceitação do próprio paciente, o dermatologista sugeria que fosse feita uma baciloscopia ou biópsia da parte lesada (por exemplo: mancha ou erupção), para a confirmação da doença.

O sexo do paciente, assim como sua situação socioeconômica, não alterou a dinâmica nem a rapidez do diagnóstico positivo para a doença entre as pessoas entrevistadas nesse estudo. A maioria recebeu diagnóstico de hanseníase muitos meses depois de ter iniciado a busca terapêutica. Um dos entrevistados foi diagnosticado depois de ter passado por muitos médicos que atendiam apenas em consultórios particulares e sem convênios. Apesar de apresentar um sintoma típico da doença, a falta de sensibilidade nos membros distais superiores e inferiores, ele percorreu vários especialistas até chegar ao centro de referência. 
A partir das narrativas dos pacientes, o diagnóstico tardio após a busca de ajuda médica parece residir, sobretudo, na falta de capacitação dos profissionais de saúde (tanto dermatologistas quanto clínicos) que atuam nas unidades básicas e centros de saúde, principalmente no interior do Estado, para realização do diagnóstico precoce.

Silva e Paz (2010) sinalizaram, em estudo realizado no município do Rio de Janeiro, que os conteúdos educativos elaborados pelo Ministério da Saúde para o treinamento dos profissionais de saúde são pouco utilizados e não estão diretamente associados ao processo de adoecimento e adesão ao tratamento dos pacientes com hanseníase. Esses profissionais, apesar de terem conhecimento da alta taxa de endemicidade da doença no país, ainda não têm experiência em lidar com o problema, o que os leva a focarem apenas a dimensão técnica do problema (passam adiante o que sabem, mas não têm noção de como isso será interpretado pelos doentes e seus familiares). Os autores argumentam que, na realidade, tais profissionais não conhecem a verdadeira necessidade desses pacientes, nem a autonomia que buscam. Com isso, não contribuem para um agir crítico, limitando suas ações aos pacientes já diagnosticados.

Esse estudo também chamou a atenção para a responsabilidade das instituições de ensino, onde poucas vezes são levantadas essas questôes. Sinaliza que a responsabilidade não deve ficar somente com os profissionais já formados para atuarem na atenção básica e demais especialidades, mas com todos aqueles que abraçaram trabalhar para a melhoria da saúde no país.

Moreno, Enders e Simpson (2008), em estudo realizado em sete municípios do Rio Grande do Norte, mostraram que os treinamentos desenvolvidos para a capacitação dos profissionais de saúde para trabalhar com a hanseníase foram eficazes, porém alguns profissionais ainda permaneceram inseguros para diagnosticar a doença.

\section{Considerações finais}

Os resultados do estudo apontam para a permanência da hanseníase enquanto um problema de saúde pública na realidade brasileira, afetando pessoas de diferentes classes sociais. As narrativas dos pacientes relevam o impacto devastador da 
doença na vida cotidiana dessas pessoas, tanto no que diz respeito ao estigma e ao preconceito quanto às limitaçôes físicas decorrentes do diagnóstico tardio. Segundo relatos dos pacientes cujos casos serviram de base para este trabalho, o tempo médio de diagnóstico foi muito longo e em muitos casos só ocorreu quando eles foram encaminhados ao centro de referência na capital do estado.

O diagnóstico tardio da hanseníase parece estar associado, de um lado, à falta de capacitação dos profissionais de saúde nos serviços de saúde para diagnosticar precocemente a enfermidade e, de outro lado, ao estigma e ao preconceito associados à hanseníase, que favorecem o silêncio em torno da doença e a prática da automedicação, os quais contribuem para o agravamento dos sintomas antes da busca de ajuda médica.

Para se atingir a meta da eliminação da doença no país é necessário que se envidem esforços em uma atuação conjunta dos governos federal, estadual e municipal na capacitação dos profissionais de saúde da atenção básica e centros especializados visando ao diagnóstico precoce e ao tratamento da hanseníase. É fundamental também que se desenvolvam ações em educação em saúde visando informar e conscientizar a população sobre a doença, e sobretudo combater o estigma e o preconceito que recaem sobre as pessoas afetadas pela hanseníase. ${ }^{1}$

\section{Referências}

ALVES, P.C.B.; SOUZA, I.M.A. Escolha e avaliação de tratamento para problemas de saúde: consideraçôes sobre itinerário terapêutico. In: RABELO, M.C.M.; ALVES, P.C.B.; SOUZA, I.M.A. Experiência de doença e narrativa. Rio de Janeiro: Fiocruz, 1999.

ALVES, P. C. B. A Experiência da Enfermidade: Consideraçōes Teóricas. Cad. Saúde Públ., Rio de Janeiro, v. 9, n. 3, p. 263-271, jul/set 1993.

ATRE, S.R. et al. Perceptions, health seeking behaviour and access to diagnosis and treatment initiation among previously undetected leprosy cases in rural Maharashtra, India. Lepr. Rev., v. 82, n. 3, p. 222-234, 2011.

BARRETT, R. Self-Mortification and the Stigma of Leprosy in Northern India. Califórnia: Stanford University Press, 2005.

BRASIL. Ministério da Saúde. Secretaria de Vigilância em Saúde. Situação Epidemiológica Hanseniase Brasil 2011. Brasília: Ministério da Saúde, 2011.

BURY, M. Illness Narratives: fact or fiction? Sociology of health and illness. Soc. of Health and Illness, v. 23, n. 3, p. 263-285, 2001. 
DE GROOT, R.; VAN BRAKEL, W.H; DE VRIES, H.J. Social implications of leprosy in

the Netherlands: stigma among ex-leprosy patients in a non-endemic setting. Lepr Rev., v. 82, n. 2, p. 168-77, 2011.

FUNDATO, C.T et al. Itinerário Terapêutico de Adolescentes e Adultos Jovens com Osteossarcoma Rev. Bras. de Cancerol. Rio de Janeiro, v. 58, n. 2, p. 197-208, 2012.

GOFFMAN, E. Estigma: notas sobre a manipulação da identidade deteriorada. Rio de Janeiro: Guanabara Koogan, 1988.

GONÇALVES, S.D; SAMPAIO, R.F; ANTUNES, C.M.F. Fatores preditivos de incapacidades em pacientes com hanseníase. Rev. Saúde Públ. São Paulo, v. 43, n. 2, p. 267-274, 2009.

JOVCHELOVITCH, S.; BAUER, M.W. Entrevista narrativa. In: BAUER, M.W.; GASKELL, G. Pesquisa qualitativa com texto, imagem e som. Petrópolis: Vozes, 2002.

KLEINMAN, A. Concepts and model for the comparison of medical systems as cultural systems. Soc. Sci. \& Med., v. 12, p. 85-93, 1978.

. The Illness Narratives. New York: Basic Books, 1988.

LINS, A. Representações sociais e hanseníase em São Domingos do Capim: um estudo de caso na Amazônia. Physis: Revista de Saúde Coletiva. Rio de Janeiro, v. 20, n. 1, p. 171-194, 2010.

MALISKA, I.C.A; PADILHA, M.I.C.S. Aids: a experiência da doença e a construção do itinerário terapêutico. Rev. Eletr. de Enferm. Goiânia, v. 9, n. 3, p. 687-698, 2007. Disponível em: http://www.fen.ufg.br/revista/v9/n3/v9n3a09.htm

MATTOSINHO, M.M.S.; SILVA, D.M.G.V. Itinerário terapêutico do adolescente com diabetes mellitus tipo 1 e seus familiares. Rev Latino-am Enfermagem. Ribeirão Preto, v. 15, n. 6, p. 1113-1119, 2007.

MINUZZO, D.A. O homem paciente de hanseníase (lepra): representação social, rede social familiar, experiência e imagem corporal. 2008. 148p. Dissertação (Mestrado em Políticas de Bem-estar em perspectiva: evolução, conceitos e actores) - Universidade de Évora, Évora, 2008. MORENO, C.M.C; ENDERS, B.C; SIMPSON, C.A. Avaliação das capacitações de hanseníase: opinião de médicos e enfermeiros das equipes de saúde da família. Rev. Bras. Enferm. Brasília, v. 61, n. especial, p. 671-675, 2008. Disponível em: http://www.scielo.br/ pdf/reben/v61nspe /a03v61esp.pdf

NATIONS, M. K; LIRA, G. V; CATRIB, A. M. Estigma, metáforas deformadoras e experiência moral de pacientes com hanseníase multibacilar em Sobral, Estado do Ceará, Brasil. Cad. Saúde Públ. Rio de Janeiro, v. 25, n. 6, p. 1215-1224, 2009.

NEVES, R.F; NUNES, M.O. Da legitimação à (res) significação: o itinerário terapêutico de trabalhadores com LER/DORT. Ciência \& Saúde Coletiva. Rio de Janeiro, v. 15, n. 1, p. 211-220, 2010. 
NICHOLLS, P.G; WIENS, C.; SMITH, W.C.S. Delay in Presentation in the Context of Local Knowledge and Attitude Towards Leprosy — The Results of Qualitative Fieldwork in Paraguay. Int. J. Lepr. Other Mycobact. Dis. Washington, v. 71, n. 3, p. 198-209. 2003.

PALMEIRA, I.P; QUEIROZ, A.B.A; FERREIRA, M.A. Quando o preconceito marca mais que a doença. Representações da saúde: abordagens contemporâneas. Tempus - Actas de Saúde Coletiva [online], v. 6, n. 3, p. 187-199, 2012. Disponível em: tempusactas.unb.br/ index.php/tempus/article/download/1163/1062

PINHO, P.A; PEREIRA, P.P.G. Therapeutic itineraries: paths crossed in the search for care. Interface - Comunic. Saúde Educ. Botucatu, v. 16, n. 41, p. 435-447, 2012.

ROMERO-SALAZAR, A. et al. The Stigma in the Social Representation of Leprosy. Cad. Saúde Públ. Rio de Janeiro, v. 11, n. 4, p. 535-542, 1995.

SANTOS, J.P. Fisioterapia em Hanseníase. Curitiba: Lovise, 1990.

SILVA, M.C.D; PAZ, E.P.A. Educação em saúde no programa de controle da hanseníase: a vivência da equipe multiprofissional. Esc. Anna Nery [online], v. 14, n. 2, p. 223-229, 2010. TALHARI, S.; NEVES, R.G. Hanseníase. Manaus: Tropical, 1997.

UCHÔA, E.; VIDAL, J.M. Medical Anthropology: Conceptual and Methodological Elements for an Approach to Health and Disease. Cad. Saúde Pública. Rio de Janeiro, v. 10, n. 4, p. 497-504, 1994.

VERONESI, R. Tratado de Infectologia. São Paulo: Atheneu, 1996.

\section{Nota}

${ }^{1}$ Este artigo é inédito, não teve financiamento e faz parte de uma pesquisa de doutorado. Os dois autores participaram juntos na construção deste artigo, com exceção do trabalho de campo, realizado pelo autor principal. 
Therapeutic itineraries of patients diagnosed with leprosy in Salvador, Babia

Leprosy and its late diagnosis, which favors the worsening of symptoms and the appearance of physical disabilities, remains a serious public health problem in Brazil. This study aims to analyze the therapeutic itinerary of patients with leprosy and understand their illness experience and the factors that contributed to late diagnosis. Eighteen narrative interviews were carried out with patients being treated for leprosy in the city of Salvador, Bahia, between 2009 and 2011. The results show that patients have experienced a long therapeutic itinerary until receiving the diagnostic. Among the factors that contributed to late diagnosis are the lack of qualification of health professionals in healthcare facilities to achieve early diagnosis, as well as the stigma and prejudice that favours the silence around the disease and the practice of self-medication.

Key words: leprosy, therapeutic itinerary, narrative analysis. 